\title{
Jogo eletrônico para o ensino de biologia celular
}

Mirian Pacheco Silva Albrecht $\frac{\text { mirian.pacheco@ufabc.edu.br }}{\text { orcid.org/0000-0003-3791-7201 }}$ Universidade Federal do ABC (UFABC) Santo André, São Paulo, Brasil

Fausto Eduardo de Oliveira biofausto2@gmail.com

orcid.org/0000-0001-8217-1126 Universidade Federal do ABC (UFABC), Santo André, São Paulo, Brasil

\section{RESUMO}

O ensino do conteúdo de permeabilidade seletiva da membrana plasmática envolve conceitos microscópicos, os quais são considerados abstratos e exigem imaginação dos alunos. Ao promover o ensino desse conteúdo, o professor pode utilizar diversos materiais didáticos, dentre eles, os jogos eletrônicos. Porém, um dos desafios enfrentados pelos professores é encontrar um jogo eletrônico relacionado com o conteúdo curricular. Nessa perspectiva, o objetivo deste texto é apresentar os resultados de uma pesquisa de mestrado na qual foi construído, aplicado e avaliado um jogo educativo que aborda conceitos de permeabilidade seletiva, como osmose, difusão simples, difusão facilitada e, transporte ativo. Como metodologia seguimos os pressupostos da abordagem qualitativa. Para o desenvolvimento da pesquisa, inicialmente, foi criado um jogo eletrônico sobre membrana celular. O jogo foi aplicado para catorze alunos de uma escola particular de Ensino Médio e, vinte alunos de uma instituição federal que cursavam a disciplina de Biologia Celular no Ensino Superior. As observações das reações e comentários dos alunos, enquanto jogavam, foram anotadas em um diário de campo. Além das observações, também aplicamos um questionário aos alunos. Tanto as anotações das observações quanto as respostas dos questionários foram utilizados como fonte de dados na investigação. Os resultados da análise interpretativa evidenciam que o jogo possui o conteúdo curricular escrito de forma opcional e não explicitado durante a partida. Os participantes descreveram o jogo como um recurso desafiador e divertido, e demonstraram que contempla o equilíbrio proposto entre a jogabilidade e o conteúdo curricular. A partir da análise sobre esses resultados, consideramos que o jogo criado pode ser utilizado, pelo professor, em qualquer nível de ensino. O conteúdo curricular presente no jogo pode ser mediado pelo professor, a partir dos objetivos da disciplina em cada nível de ensino.

PALAVRAS-CHAVE: Membrana Plasmática. Ensino de Biologia. Aprendizagem. Jogos Eletrônicos. 


\section{INTRODUÇÃO}

A membrana plasmática é um envoltório presente em todos os tipos celulares e confere às células a capacidade de manter sua composição química interna, por certo tempo, independentemente da composição do meio externo. Isso ocorre através do controle de troca de substâncias entre os meios interno e externo, o que é conhecido como "permeabilidade seletiva". Ensinar esse conteúdo na escola é desafiador para os professores, pois, por ser um tema que envolve conceitos microscópicos, exige dos alunos capacidade de compreensão e de abstração, para formular mentalmente os processos de troca celular. Tais processos podem ocorrer de diversas maneiras, e nem toda substância ou partícula pode atravessar diretamente a membrana (JUNQUEIRA; CARNEIRO, 2012).

Em uma pesquisa sobre o ensino de conteúdos de Biologia, realizada por Petrovich et al. (2014) com estudantes de licenciatura em Ciências Biológicas, o conteúdo de Biologia Celular foi considerado como o mais difícil de ensinar. Para Leão (2018, p. 35-6), “a Biologia Celular é uma matéria que envolve conceitos extremamente abstratos para o(a) estudante, pois a grande maioria dos objetos estudados está abaixo do limite de resolução do olho humano". Os conceitos abstratos estão relacionados com as ideias e associações que os alunos realizam para o entendimento e apropriação do conteúdo. Segundo Almeida e Junior (2018, p. 173) "Abstrair é uma forma de representar as ideias e suas associações que não estão diretamente relacionados à realidade. Um conceito abstrato pode ser mais ou menos concreto dependendo do contexto".

Vigário (2017, p. 45) aponta que "ensinar e aprender não são tarefas fáceis, principalmente quando é preciso partir da abstração sobre um assunto para se chegar à concretização de um conceito ou de um processo." Esta visão sobre o aspecto da abstração na aprendizagem de Biologia Celular também é discutida por Cunha (2011, p. 34), ao afirmar que "este tema é conceitualmente abstrato e sua aprendizagem, apesar das diferentes estratégias hoje conhecidas para favorecê-la, ainda encontra dificuldades na sua compreensão". Com efeito, as estratégias formuladas para a aprendizagem das gerações passadas podem não ser adequadas para o aprendizado desta geração atual, uma vez que a maneira de aprender difere de uma geração para outra (PRENSKY, 2010).

O aluno da atual geração está imerso em um mundo permeado por imagens, sons e movimentos de maneira não linear. Ao discutir que a imaginação e o processo de produção do conhecimento científico estão relacionados, Leão (2018, p. 37) destaca que "para a Biologia Celular, a necessidade da formação de representações não linguísticas é particularmente importante, tendo em vista as especificidades da matéria". Por essa razão, dentre a diversidade de materiais didáticos existentes para o ensino da Biologia Celular, apontamos que o jogo pode ser uma estratégia de ensino que atende aos anseios da geração atual. Para Meir et al. (2005), os jogos eletrônicos podem proporcionar mais realismo e dinamismo ao ensino dos processos celulares através da simulação.

Ao incorporar desafios em níveis progressivos de dificuldade e apresentar objetivos que geralmente são descobertos pela exploração, os jogos podem ser considerados educativos, pois atendem ao ritmo de aprendizagem de cada estudante. Soares (2013, p. 48) aponta que "[...] todo jogo é, em si, educativo em sua essência". Segundo o autor, "a ideia de jogo educativo quer aproximar o 
caráter lúdico existente no jogo à possibilidade de se aproximar o desenvolvimento cognitivo" (p. 45).

Para Lalueza, Crespo e Camps (2010, p. 51) apontam que, "sem dúvida nenhuma, a nova ferramenta mais estudada no que se refere ao seu impacto no desenvolvimento cognitivo, social e emocional é a dos videogames [...]". Isso ocorre porque a maioria dos jogos, principalmente os eletrônicos, são atrativos aos jovens.

Porém, são raros os jogos que contemplam um equilíbrio entre conteúdos curriculares, como Biologia Celular, por exemplo, e a jogabilidade, ou seja, algo que relacione o controle do jogo com o design e a experiência de jogar. Para Mello (2013, p. 123), "apontar um conceito unificado para a jogabilidade esvaziaria a riqueza de significados e abordagens realizadas com o termo, tendo em vista suas muitas variáveis definidoras." Para o autor há uma relação de "complementaridade entre agência, interface e interação como unidades a interagirem entre si e formarem a base da jogabilidade."

Por outro lado, Amaro (2016, p. 59), aponta a "jogabilidade como um processo pertencente ao universo da usabilidade, só que acrescentados de alguns aspectos, como o prazer e o nível de aprendizagem a partir dos obstáculos, restritos aos jogos. Portanto, neste texto, o termo jogabilidade é associado a um conjunto de fatores que dizem respeito principalmente ao prazer de jogar" e "controlar" o jogo.

Assim, visando contribuir com as discussões sobre jogos eletrônicos educativos, neste artigo, apresentamos os resultados de uma pesquisa de mestrado que teve como objetivo o desenvolvimento de um jogo eletrônico educativo. Dados parciais da pesquisa já foram publicados em eventos da área, porém neste artigo apresentamos os dados aprofundados e ampliados. Ressaltamos que esse jogo pode ser utilizado como recurso didático para o ensino de conteúdos de Biologia, especificamente sobre a permeabilidade seletiva da membrana plasmática.

\section{METODOLOGIA}

A pesquisa seguiu os pressupostos da abordagem qualitativa, ocorreu em um cenário natural e procurou explorar a significação e a opinião dos participantes em relação a um evento (CRESWELL, 2010). O evento explorado foi relacionado à criação, testagem e avaliação de um jogo eletrônico. O desenvolvimento da pesquisa ocorreu entre os anos de 2014 e 2015. Todos as observações sobre o evento foram registradas em um diário de campo. Conforme Creswell (2010), o diário de campo é um instrumento do pesquisador para registrar as notas das observações realizadas no campo.

As etapas para a constituição de dados foram: criação do jogo, teste piloto e avaliação. Na etapa de criação do jogo foram seguidos os 14 parâmetros de desenvolvimento de jogos eletrônicos educativos citados por Klopfer, Osterweil e Salen (2009), os quais são aqui descritos resumidamente, são eles: 1 - Sabedoria: Não esperar que o jogo seja o recurso didático definitivos para todas as pessoas, temas e contextos; $\mathbf{2}$-Simplicidade: Pode ser desenvolvido um jogo simples, mas que contemple adequadamente os objetivos pedagógicos; $\mathbf{3}$ - Jogos educativos são diferentes dos jogos comerciais: Eles não precisam conter todos os atributos 
gráficos ou de jogabilidade de um game comercial; 4 - Ênfase no aprendizado e na jogabilidade: Equilibrar o conteúdo com a diversão; 5 - Encontrar a dinâmica do jogo dentro do conteúdo: Eleger os elementos chaves da disciplina que podem ser representados em jogos, não sendo necessário abordar todo o conteúdo curricular; 6 - Pense em diferentes ambientes para se jogar os jogos: Pensar que um jogo educativo pode ser jogado tanto na escola quanto fora dela; 7 - Aproveite o desenvolvimento de habilidades ligadas ao conteúdo: Habilidades como a resolução de problemas, raciocínio, ética, comunicação e trabalho em grupo devem ser pensadas em conjunto com o conteúdo; 8 - Pense na questão do professor: $\mathrm{O}$ jogo pode proporcionar ao professor a possibilidade de mediação ou intervenção, sem exigir reformulação total do seu planejamento; 9 - Jogos para se jogar em qualquer lugar: Pensar em jogos para dispositivos móveis, fáceis de carregar, como celulares. 10 - Reduza, reuse e recicle: $O$ custo da produção de um game educativo muitas vezes é um fator limitante para sua conclusão; 11 - Defina os objetivos de aprendizagem: Estabelecer os objetivos de aprendizagem e de que maneira estes objetivos serão avaliados; 12 - Busque parcerias: Visando otimizar os custos e o tempo de produção de jogos é interessante buscar parcerias com entidades ligadas com o desenvolvimento de jogos; 13 - Não seguir à risca os padrões acadêmicos ou do Estado: Refletir sobre inovação; 14 - Pensar em quem, o que, onde, quando e por quê: Contemplar não só o contexto onde ele será jogado, mas também onde ele será vivenciado e o contexto onde está inserido não só o aluno, mas o professor mediador e seus colegas.

Para a etapa de criação utilizamos o software livre Game Maker Studio, disponibilizado pela YoYo Games e desenvolvido para dispositivos com sistema operacional Windows superior à versão XP. Vale ressaltar que esse jogo não é executável em sistema Linux ou MAC.

Para o teste piloto, contamos com a colaboração de um professor de Biologia e com estudantes do Ensino Médio Regular de uma escola particular no estado de São Paulo. Os sujeitos foram 14 alunos, com idades entre 15 e 17 anos, estudantes de uma mesma sala do primeiro ano do Ensino Médio. Os dados dessa etapa foram constituídos por meio de observações e questionário. As observações foram realizadas enquanto os alunos jogavam e foram registradas em um diário de campo. O questionário foi respondido pelos alunos e objetivava compreender as relações dos sujeitos de pesquisa com jogos e coletar sugestões de melhoria.

Para a etapa de avaliação aplicamos o jogo no Ensino Superior com duas turmas, que somavam 20 alunos que cursavam a disciplina de Biologia Celular, em uma universidade pública. A participação dos alunos foi voluntária e houve a assinatura do Termo de Consentimento Livre e Esclarecido, portanto não houve critério para seleção dos sujeitos. Utilizamos um diário de campo para registro das observações dos alunos enquanto jogavam.

Também aplicamos um questionário baseado na combinação de alguns aspectos da metodologia Learn Object Review Instrument (LORI), um instrumento que fornece métricas para classificar o objeto de aprendizagem por meio de nove itens: qualidade do conteúdo, alinhamento do objetivo de aprendizagem, feedback e adaptação, motivação, design da apresentação, usabilidade, acessibilidade, reusabilidade e, aderência a padrões (SOUZA et al, 2018). O questionário foi construído com quatro questões, são elas: 1 - Qual a sua opinião sobre a quantidade e a qualidade do conteúdo curricular apresentado no jogo? 2 - 
Como você avalia o layout e o visual do jogo? 3 - Qual a sua opinião sobre a experiência de entretenimento e diversão proporcionada pelo jogo? 4 - Como você utilizaria o jogo para o ensino do tema?

A análise dos dados foi realizada de modo diferenciado para cada uma das três etapas: criação do jogo, teste piloto e, avaliação. Na etapa de criação do jogo, foram analisados seus componentes artísticos, os aspectos visuais dos personagens, o plano de fundo, as substâncias, os elementos informativos e os menus. Essa análise decorreu de constantes testes e alterações na coloração, no brilho, no contraste, nas dimensões e resultou também do posicionamento desses elementos, objetivando proporcionar um layout limpo e de fácil entendimento, conforme proposto por Klopfer, Osterweil e Salen (2009).

$\mathrm{Na}$ etapa do teste piloto, buscamos indicadores de reações, atitudes e comportamentos dos participantes nos dados registrados nas anotações do diário de campo. E também buscamos identificar a existência de um padrão de repetição nas sugestões de melhoria que foram apresentadas nos questionários.

Na etapa de avaliação, fizemos a leitura das respostas dos participantes a cada uma das quatro questões do questionário. Após identificar a frequência de repetições ou similaridades, realizamos uma análise interpretativa das respostas e, a partir dos 14 parâmetros citados por Klopfer, Osterweil e Salen (2009), criamos quatro categorias de análise: conteúdo curricular; Layout e visual do jogo; Jogabilidade; e Uso pedagógico do jogo.

É válido enfocar, que esta investigação foi analisada e aprovada pelo Comitê de Ética em Pesquisa da Universidade Federal do $A B C$ com o número do parecer 1.056.020. (CAAE no 1.056.020. 41837215.6.0000.5594, 08 de maio de 2015).

\section{RESULTADOS E DISCUSSÕES}

\section{CRIAÇÃO DO JOGO}

O jogo foi produzido com a utilização de um computador com acesso à internet e o software livre de criação de jogos: Game Maker Studio. Na primeira etapa, criação do jogo, foram desenvolvidos os elementos: célula, moléculas, íons, o plano de fundo e, todas as telas que compõem o jogo: tela de menu principal; tela de tutorial; telas de conteúdos; e tela de abertura. Segundo Gee e Shafer (2012), um bom jogo educativo deve possuir elementos similares à estrutura do objeto de estudo, e esses elementos devem ser perceptíveis ao jogador enquanto joga.

A percepção e a significação desses elementos são indispensáveis para que se consiga atingir os objetivos pedagógicos propostos pelo jogo. A figura 1, a seguir, representa o elemento célula finalizado. 


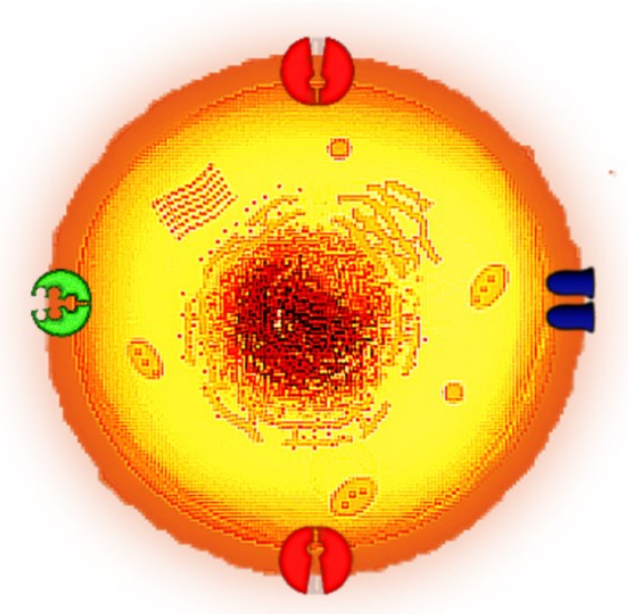

Fonte: Autoria própria (2015).

Depois da criação do elemento célula foram produzidos os itens que ela coleta durante o jogo: as moléculas de água e de oxigênio e; os íons Sódio e Potássio. Conforme a figura 2, esses itens são representados em sua forma molecular, proporcionando maior facilidade ao aluno para compreender a relação entre cada molécula ou íon absorvido e cada tipo de transporte celular.

Figura 2 - Moléculas- Moléculas de água e de oxigênio e os íons Sódio e Potássio

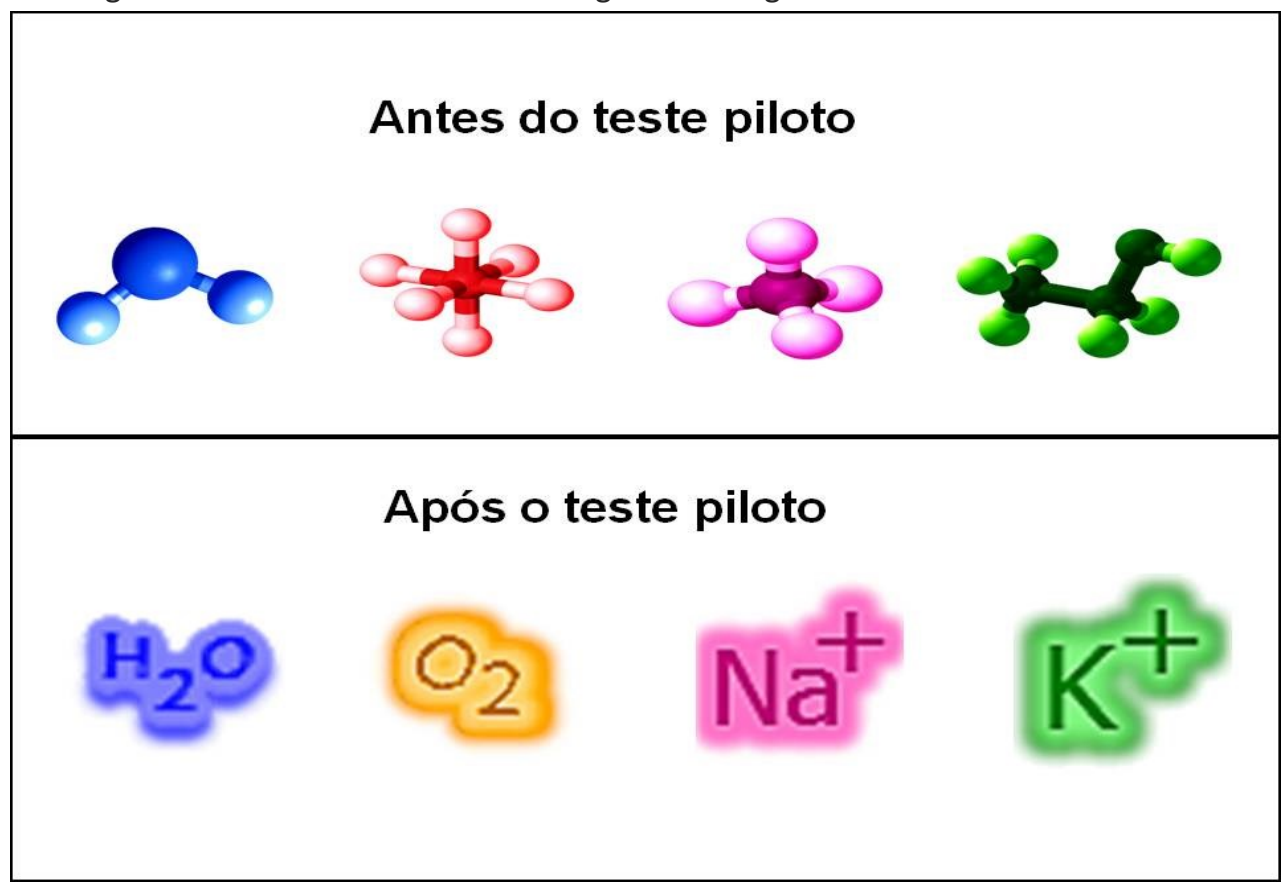

Fonte: Autoria própria (2015).

No final da produção do jogo foram construídos o plano de fundo, os botões de comando e os blocos informativos. Segundo Bordenave e Pereira (2011), as figuras, textos, títulos e demais elementos informativos que compõem o layout de 
um jogo possuem certo impacto visual sobre a atenção do jogador. O centro de interesse deve ser pensado como o primeiro estímulo a ser percebido pelo aluno, ele deve se destacar dos demais componentes visuais. Os blocos de massas ou blocos informativos servem para informar o jogador sobre algum dado referente ao seu desempenho na partida. Como são elementos secundários não devem ocupar posição de destaque, por outro lado também precisam ficar visíveis ao jogador. A figura 3 representa o layout da quarta e última fase do jogo, evidenciando, no centro, a célula e sua membrana, com as proteínas transportadoras, rodeadas pelas moléculas e pelas substâncias. Nas margens são evidenciados os blocos de massas.

Figura 3 - Quarta e última fase do jogo

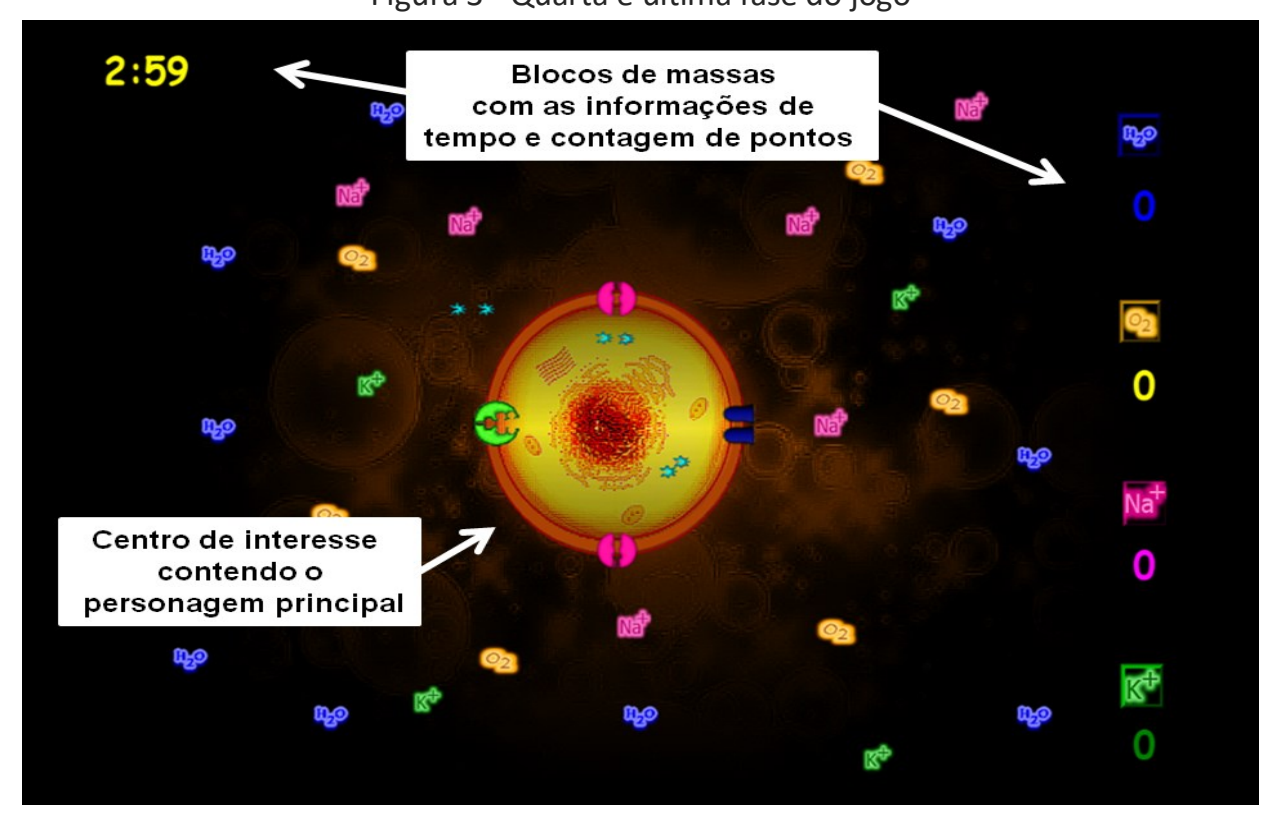

Fonte: Autoria própria (2015).

A figura 4 representa a tela de abertura do jogo, informando aos jogadores os objetivos, os créditos de produção e a licença do jogo. Esta tela de apresentação, também chamada de Splash, evidência a proteção aos direitos autorais firmada por uma licença Creative commons. 
Figura 4 - Tela de abertura do jogo

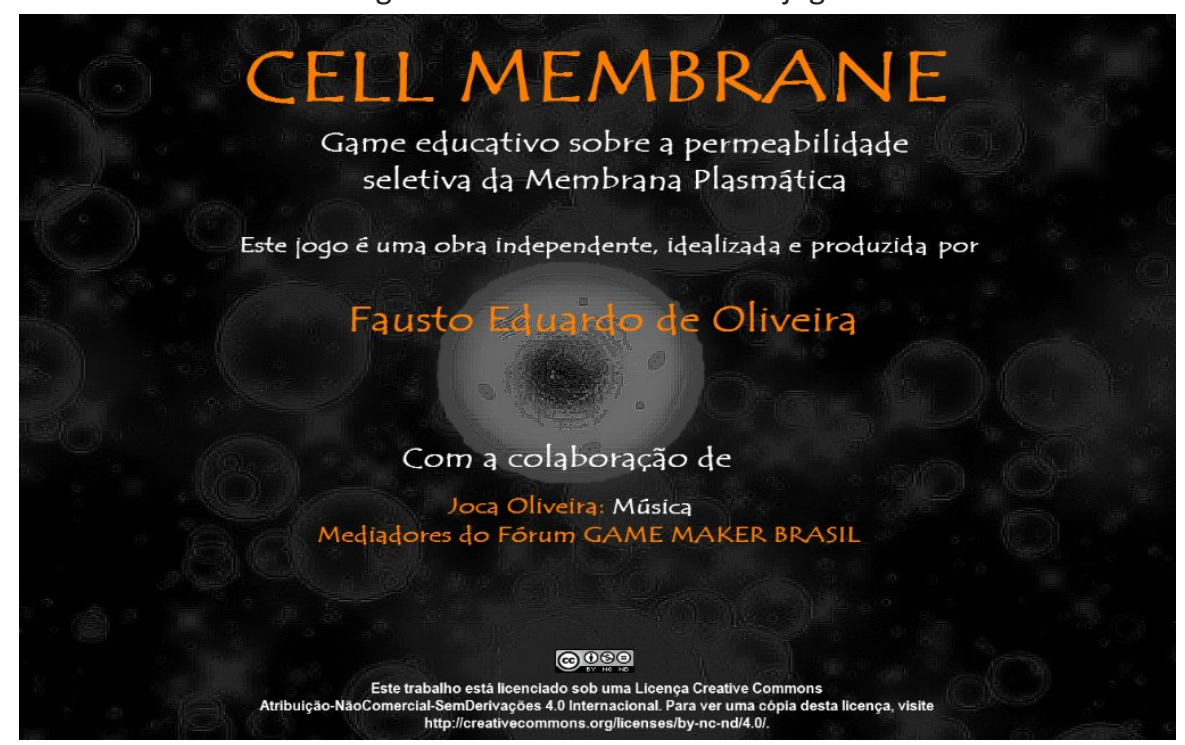

Fonte: Autoria própria (2015).

Para iniciar o jogo, por meio da tela de abertura, o jogador acessa o menu principal e pode escolher em qual das quatro fases deseja jogar: osmose, difusão simples, difusão facilitada ou transporte ativo. Ou pode escolher um nível de desafio maior, optando pelo ícone "Mais desafio?". Nesta fase especial, o jogador terá os quatro processos de troca de substâncias ao mesmo tempo, mas com um número maior de moléculas, que circulam com uma maior velocidade pela tela. As explicações sobre o conteúdo e sobre o modo de jogar foram inseridas por meio de duas opções de menu: "Tutorial" e "Conteúdo". O menu "Tutorial" pode ser acessado a partir do menu principal e mostra os comandos do jogo, apresentados na figura 5.

Figura 5 - Representação da tela do menu principal

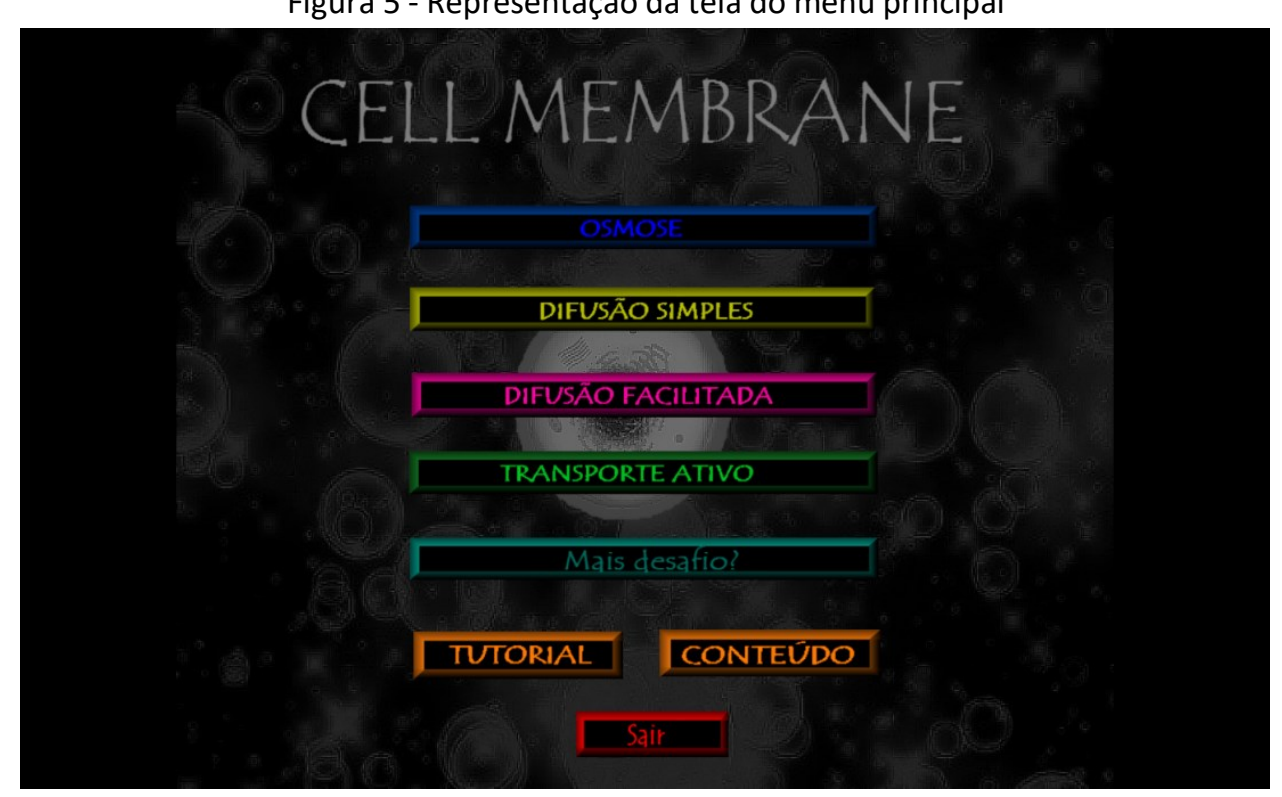

Fonte: Autoria própria (2015). 
São utilizadas para movimentação as teclas de setas direcionais do teclado do computador, e as teclas SPACE, ENTER e ESC servem para movimentar as substâncias, iniciar e finalizar o jogo, respectivamente, conforme figura 6.

Figura 6 - Tela do menu tutorial

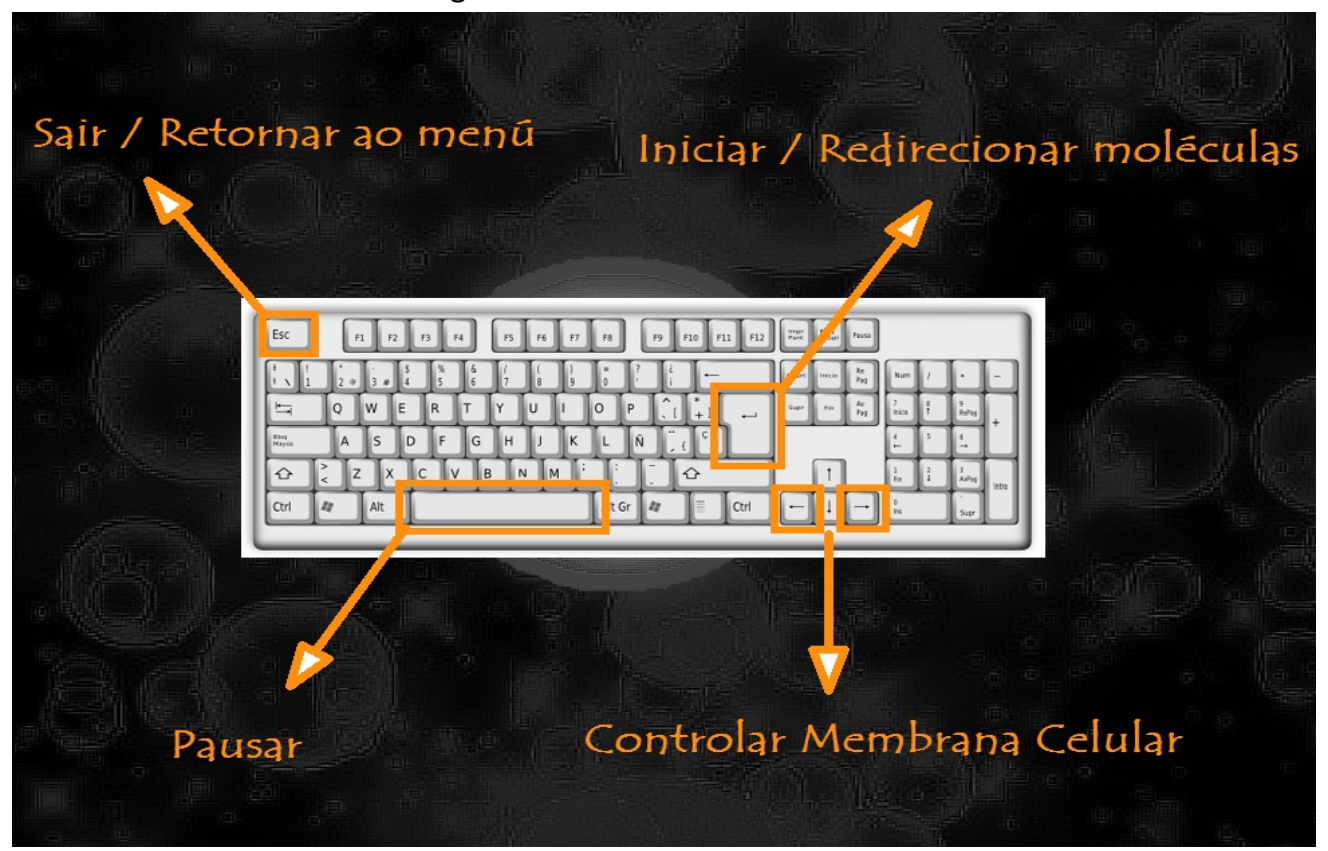

Fonte: Autoria própria (2015).

Este jogo foi idealizado seguindo os parâmetros descritos postulados por Klopfer, Osterweil e Salen (2009). O foco é na dinâmica da resolução de problemas pelo próprio aluno, através da exploração do jogo. O jogador deve ser convidado a "aprender fazendo", por tentativa e erro. Ou seja, o jogador deve ser livre para errar, pois esses erros são exatamente os mecanismos que proporcionam a aprendizagem. Livres para experimentar e interpretar, os jogadores testam diversas possibilidades, para encontrar a maneira correta de realizar uma ação.

Segundo o relatório de Klopfer, Osterweil e Salen (2009), The Education Arcade, do Massachusetts Institute of Technology, os jogos educativos não devem priorizar nem o conteúdo, sob risco de se tornar apenas mais uma tarefa imposta, e nem a diversão, pois não se atingiriam os objetivos de aprendizagem. $O$ jogo sobre a membrana celular foi baseado nesta proposta de equilíbrio, e por isso não possui frases, textos, informações ou questionamentos a respeito do conteúdo curricular durante a partida. Dessa forma, não se aborda o conteúdo explicitamente, o que permite ao aluno essa livre interpretação e exploração através dos símbolos e dos signos, com o intuito de que ele construa seu conhecimento pela pesquisa externa e, principalmente, na interação com o professor.

Para a proteção dos direitos autorais, o jogo sobre membrana celular foi licenciado pela Creative Commons (CC), uma entidade sem fins lucrativos que objetiva flexibilizar e facilitar a utilização de obras protegidas por direitos autorais, permitindo que o autor amplie o uso de seus materiais por terceiros, sem que estes infrinjam leis de proteção à propriedade intelectual. $\mathrm{O}$ jogo foi criado com uma licença 4.0 CC BY-NC-ND (Atribuição-SemDerivações-SemDerivados), e está 
disponível somente por compartilhamento com atribuição de créditos, sem a possibilidade de alteração ou de utilização com fins comerciais. 0 download pode ser acessado por meio do link: https://www.dropbox.com/s/9vv1tid4w2huqrt/cell\%20membrane\%20-Default1.0.0.2.exe? $\mathrm{dl}=0$.

\section{TESTE PILOTO}

O teste piloto foi realizado com estudantes do Ensino Médio, em uma aula de revisão de conteúdo de Biologia. Utilizamos um computador com projeção e, com um data show, mostramos o jogo e os comandos dele para toda a classe, mas não revelamos aos alunos como jogar. Solicitamos dois voluntários para conduzir o jogo e nesse momento observamos sem interferir ou dar opiniões. Durante o manuseio pelos dois alunos voluntários, a curiosidade e a motivação foram evidentes em toda a classe, pois os outros alunos começaram a apresentar ideias e sugestões sobre como explorar e entender o jogo. Soares (2013, p. 45), aponta que, ao propiciar a livre exploração dos alunos, o jogo possibilita uma aproximação do "caráter lúdico com o desenvolvimento cognitivo". Nesta situação aqui relatada, isso ficou bem evidente, pois os alunos discutiram e elaboraram hipóteses sobre o que fazer para avançar no jogo e, ao associarem as regras do jogo com as leis que regem os transportes pela membrana celular, relembraram o conhecimento que construíram sobre o conteúdo curricular.

Após o término do jogo, os alunos preencheram a segunda parte do questionário, cujo objetivo era a análise e apresentação de sugestões para modificações. As respostas da segunda parte evidenciaram que os alunos gostaram do jogo. Mesmo aqueles que não tinham familiaridade com jogos eletrônicos o consideraram interessante e útil. Além de gostarem, eles apresentaram algumas sugestões de modificação relacionadas à estrutura, à forma e ao layout do jogo. Na figura 7, utilizada no teste piloto, as moléculas em sua forma estrutural representavam as substâncias absorvidas pela célula.

Figura 7 - Quarta fase do jogo proposta no teste piloto

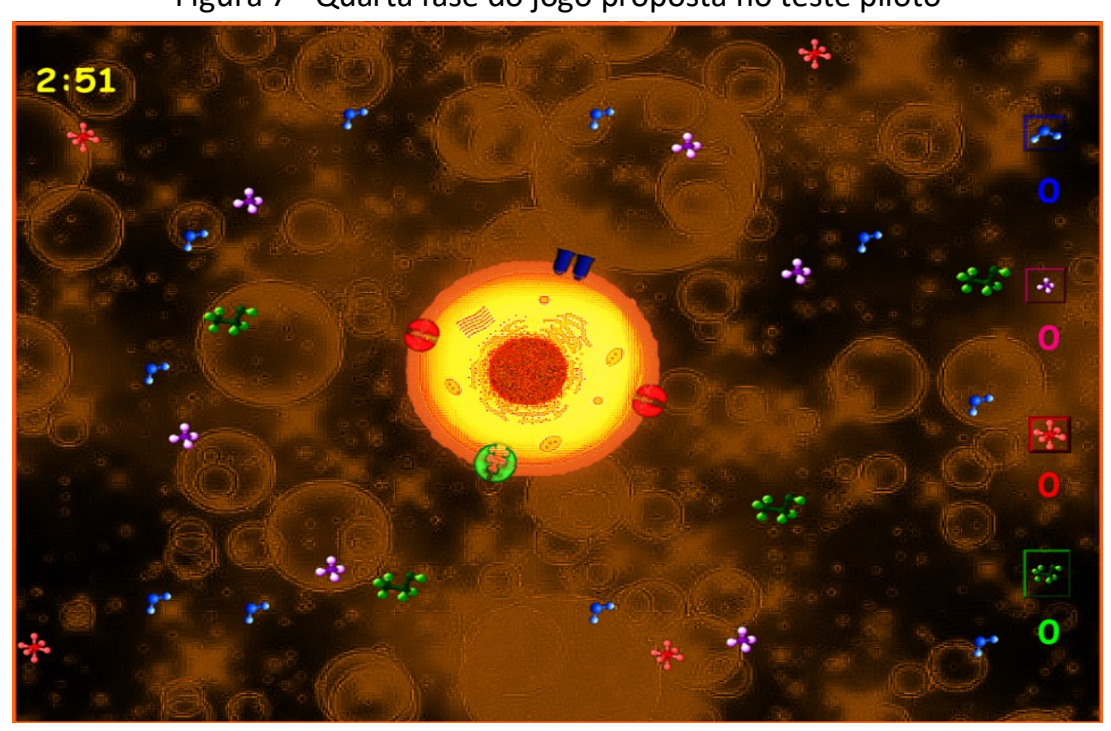


Os alunos sugeriram que a representação das moléculas em forma estrutura fossem substituídas pela forma molecular, conforme figura 8. Assim há uma melhor compreensão de qual substância participa de cada transporte específico. Outra sugestão de melhoria envolveu a adição de partículas de soluto nos meios intra e extracelular, aumentando assim a abrangência de conteúdos a serem explorados durante o jogo, interligando-o a conceitos físico-químicos. Essas partículas também podem ser observadas na figura 8 e são representadas por quatro pequenos pontos verdes e estrelados dentro da célula e dois pontos verdes e estrelados fora dela.

Figura 8 - Quarta fase do jogo modificada após teste piloto

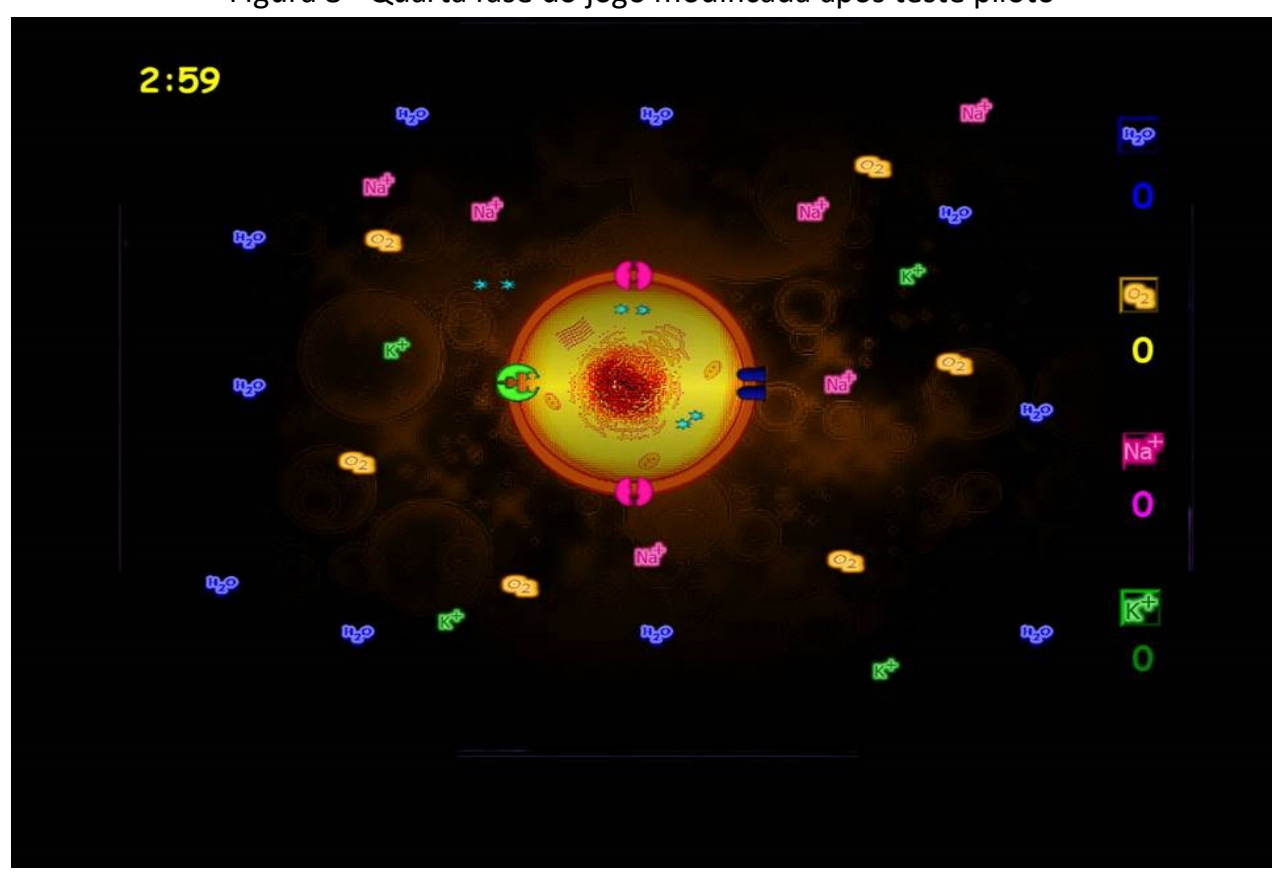

Fonte: Autoria própria (2015).

Um fato curioso desta última sugestão é que o jogo possuía uma lacuna no processo de transporte ativo. Este tipo de transporte não ocorre como nos outros três: osmose, difusão simples e difusão facilitada, pois as moléculas não passam livremente, e é necessária a troca de moléculas; ou seja, para que a célula incorpore moléculas de Potássio, é preciso que ela tenha moléculas de Sódio e que as troque. Por dificuldades na programação, o jogo ainda não contemplava esta regra, o que constituía em uma falha conceitual, apontada pelos alunos, e que foi resolvida após o teste piloto.

\section{AVALIAÇÃO DO JOGO}

Após as modificações que foram sugeridas pelos alunos no teste piloto, realizamos a avaliação. Para isso, o jogo foi aplicado em duas turmas de alunos que cursavam a disciplina de Biologia Celular, no Ensino Superior. Utilizamos um computador conectado a um projetor Data Show para a apresentação do jogo aos alunos. Na sequência, solicitamos dois participantes voluntários para jogarem. Eles 
manipularam o jogo, porém todos os alunos da classe acompanharam e interagiram com os jogadores em busca da solução.

Prensky (2010) diz que os jogos eletrônicos educativos despertam muito mais interesse que uma aula comum, pois provocam a participação ativa dos alunos, na tentativa de solucionar um problema em conjunto. Este interesse pôde ser evidenciado pelas observações na sala durante a aplicação do jogo. No início da aula poucos alunos estavam concentrados no jogo, mas, à medida que eles foram manifestando entusiasmo e alegria, os outros alunos, que estavam dispersos, foram se interessando, e rapidamente estavam envolvidos na busca da solução para os desafios. Meir et al. (2005), afirma que os jogos podem ajudar no ensino de conteúdos de Biologia Celular, pois podem proporcionar mais realismo aos processos celulares, além de facilitar a representação mental.

Finalizado o jogo, os alunos responderam ao questionário que possuía quatro perguntas, conforme descrito na metodologia. A análise do questionário ocorreu de modo interpretativo a partir das quatro categorias que foram criadas. $\mathrm{Na}$ categoria conteúdo curricular identificamos que os alunos aprovaram a maneira como o conteúdo curricular foi abordado no jogo, considerando-a como "boa" e "ótima" e ponderaram que a qualidade e a quantidade do conteúdo curricular não atrapalharam a jogabilidade. Isso corrobora a ideia de Klopfer, Osterweil e Salen (2009), quando citam que um bom jogo eletrônico educativo deve ser construído em um equilíbrio entre conteúdo curricular e jogabilidade.

Em relação a categoria layout e visual do jogo, os alunos responderam no questionário que consideravam simples e de fácil entendimento. Dessa maneira, entendemos que o layout não tenha afetado a jogabilidade ou o entendimento do conteúdo. Contudo, durante a aula observamos que alguns alunos das duas turmas se movimentaram, na tentativa de enxergar algo melhor, e isso se deu por causa da cor azul utilizada nas moléculas de água, que não eram bem visíveis de alguns pontos da sala, devido à interferência da luz solar que entrava pela janela. Este é um importante aspecto de melhoria nesse jogo e também para futuros jogos, uma vez que muitos ambientes escolares carecem de isolamento eficiente da luz solar, e essa interferência pode contribuir para o desinteresse de alguns alunos.

As palavras mais encontradas nas respostas do questionário, relacionadas à categoria jogabilidade, foram "desafiador e "divertido", além de muitas outras com significados similares, indicando que os participantes consideraram a jogabilidade boa. Esses aspectos indicam que a jogabilidade, quando em uma aula coletiva, proporciona a imersão,a integração e a interação dos alunos no tema da aula, o que faz do jogo uma alternativa para facilitar os processos de ensino e aprendizagem. Assim, apontamos que o jogo pode servir como uma alternativa complementar à teoria. Este aspecto se encaixa no que diz Kenski (2003) sobre o aluno aprender por exploração e descoberta. A maneira como o jogo foi utilizado em sala proporcionou aos alunos essa exploração e descoberta por eles mesmos, enquanto ao professor coube o papel de dialogar com eles, fornecendo pistas e feedback para que eles próprios solucionassem os desafios do jogo.

Em relação à categoria uso pedagógico do jogo, os participantes responderam no questionário que dão preferência a uma metodologia que envolva a sala coletivamente, como uma equipe que investiga e soluciona os problemas propostos pelo jogo. Houve também sugestões de utilização individual, com um 
computador por aluno, e a divisão da sala para uma disputa em equipes. Isso corrobora o que Krasilchik (2008) e Lévy (2010) dizem sobre os benefícios da utilização de mídias interativas para facilitar a imaginação e desmistificar conceitos microscópicos e abstratos.

Outro ponto a se considerar a respeito da utilização do jogo sobre membrana celular é o que diz Soares (2013) sobre a aquisição de conhecimentos: mesmo que os alunos não tenham aprendido o conteúdo diretamente através da aula com o jogo, a simulação dos processos de troca da membrana plasmática pôde fornecer dinamismo a imagens e símbolos, auxiliando no processo de abstração do funcionamento desses fenômenos microscópicos.

\section{CONSIDERAÇÕES FINAIS}

Na pesquisa analisamos o processo de criação, testagem e avaliação de um jogo eletrônico sobre membrana celular. Para a criação do jogo, inicialmente foi necessário ampliarmos nossos conhecimentos sobre software de criação de jogos. Os elementos do jogo foram criados individualmente: primeiro a célula, depois as moléculas e os íons, o plano de fundo e as telas que compõem o jogo.

Após a criação da primeira versão do jogo realizamos um teste piloto com alunos do Ensino Médio. A partir dessa etapa, foram feitas melhorias, e o jogo final ficou estruturado em quatro fases, correspondentes aos processos de: osmose, difusão simples, difusão facilitada e transporte ativo. Além de criar um nível gradativo de dificuldade, ao somar um processo diferente a cada fase, também se objetivou não compartilhar uma visão fragmentada das funções celulares, proporcionando a percepção de que a célula está em constante atividade e que possui a capacidade de realizar diversos processos simultâneos.

A avaliação do jogo foi realizada a partir da sua aplicação no Ensino Superior, com participação e envolvimento dos alunos, na tentativa de solucionar os desafios do jogo. Avaliamos que muitos dos obstáculos encontrados pelos jogadores só poderiam ser solucionados pelo conhecimento do conteúdo dos processos de trocas da membrana plasmática. Ao longo de toda esta etapa, assumimos o papel de professor mediador do conhecimento e, à medida que os alunos se lembravam de alguns aspectos relacionados ao conteúdo e contribuíam verbalmente para a resolução do problema, atribuíamos sentido a essas sugestões e facilitavamos o aprendizado do tema. Diante dos resultados obtidos na avaliação do jogo, é possível afirmar que, para se obter um resultado satisfatório na utilização deste jogo em sala de aula, a intervenção do professor é importante para fazer a mediação com o conteúdo.

Assim, apontamos que o jogo eletrônico sobre membrana celular pode ser utilizado tanto no Ensino Médio quanto no Ensino Superior, pois possui o conteúdo curricular escrito de forma opcional e não explicitado durante a partida. Portanto, é o professor que irá transpor o conteúdo curricular ao jogo, é ele que definirá qual sentido a simulação, os desafios e os objetivos do jogo terão para os alunos. Isso também evidencia o caráter adaptável do jogo a diversas situações. Contudo, é preciso compreender que ele não é um produto definitivo que vai solucionar as dificuldades de compreensão de todos os alunos, pois um jogo eletrônico pode ser estimulante para um grupo de alunos e pode, também, não ser para outro, pois 
existe uma diversidade de gêneros e estilos de jogos e também há alunos que não se sentem atraídos pelos jogos eletrônicos. Diante deste aspecto, cabe ao professor conhecer o jogo e, principalmente, conhecer o público que o utilizará, para planejar uma metodologia que interligue os alunos ao conteúdo apresentado no jogo.

Por fim, consideramos que a utilização desse tipo de jogo é importante, pois, devido ao seu caráter microscópico, poderá ajudar os alunos com dificuldades em entender os conteúdos de Citologia. Portanto, concluímos que os jogos educativos podem funcionar como bons materiais didáticos para o processo de ensino e aprendizagem. O tema Citologia é um campo fértil para o desenvolvimento de jogos, pois suas estruturas e os processos podem ser explorados por desenvolvedores de jogos eletrônicos e professores, com o intuito de atribuir mais realismo e dinamismo ao abstrato e microscópico mundo das células. No entanto, vale ressaltar que é muito importante que o professor discuta, durante a utilização do jogo, os limites de validade contidos no modelo representacional e nos conceitos científicos abordados, como por exemplo, as diferenças das dimensões e proporcionalidade entre o modelo apresentado e o objeto real. Esperamos que novas pesquisas sobre jogos eletrônicos para o ensino de Biologia Celular possam surgir, no intuito de analisar as contribuições que os jogos podem oferecer ao Ensino de Ciências. 


\title{
Electronic game for cell biology teaching
}

\begin{abstract}
Teaching of selective permeability content of the plasma membrane involves microscopic concepts, which are considered abstract and require students' imagination. When promoting teaching of this content, teachers can use several didactic materials, among them, electronic games. However, one of the challenges faced by teachers is to find an electronic game related to the curriculum content. From that perspective, the aim of this text is to present the results from a master's research in which an educational game was built, applied, and evaluated that deals with concepts of selective permeability, such as osmosis, simple diffusion, facilitated diffusion and, active transport. As a methodology, we follow the assumptions of the qualitative approach. For the development of the research, initially, an electronic game about the cell membrane was created. The game was applied to fourteen students from a private high school and twenty students from a federal institution who were studying Cell Biology in Higher Education. Observations of students' reactions and comments while playing were writen down in a field notebook. In addition to the observations, we also applied a questionnaire to students. Both notes of the observations and answers to the questionnaires were used as a data source in the investigation. The results of the inductive analyses show that the game has the curriculum content written optionally and not explained during the game. Participants described the game as a challenging and fun resource and demonstrated that it takes into account the proposed balance between gameplay and curriculum content. From the analysis of these results, we consider that the game created can be used, by teachers, at any level of education. The curricular content present in the game can be mediated by the teacher, based on the goals of the subject, for every level of education.
\end{abstract}

KEYWORDS: Plasma Membrane. Biology teaching. Learning. Electronic games. 


\section{REFERÊNCIAS}

AMARO, M. Eu não posso ser dois: uma perspectiva sobre o conceito de gameplay a partir de experimentos com o jogo brothers - a tale of two sons. 2016. 309 f. Dissertação (Mestrado) - Curso de Comunicação e Informação, Universidade Federal do Rio Grande do Sul, Porto Alegre, 2016. Disponível em: https://lume.ufrgs.br/handle/10183/142834 Acesso em: 10 mar. 2020.

ALMEIDA, H. A.; LORENCINI-JUNIOR, A. As concepções de um professor de Biologia quanto ao uso de analogias na prática docente. ACTIO, Curitiba, v. 3, n. 2, p. 173-194, mai./ago. 2018. Disponível em:

https://periodicos.utfpr.edu.br/actio/article/view/8085/5285 Acesso em: 23 ago. 2020.

BORDENAVE, J. D; PEREIRA, A., M. Estratégias de ensino-aprendizagem. 31 ed. Petrópolis: Vozes, 2011.

CRESWELL, J. W. Projeto de pesquisa: métodos qualitativo, quantitativo e misto. 3 ed. Porto Alegre: Artmed, 2010.

CUNHA, K. M. C. O ensino e a aprendizagem significativa da célula no contexto da disciplina Biologia do primeiro ano do ensino médio em uma escola pública do Rio de Janeiro. 2011. Dissertação (Mestrado em Biociências e Saúde) Instituto Oswaldo Cruz, Rio de Janeiro, 2011. Disponível em: https://www.arca.fiocruz.br/handle/icict/4061 Acesso: 12 mar. 2020.

JUNQUEIRA, L. C.; CARNEIRO, J. Biologia celular e molecular. 9 ed. Rio de Janeiro: Guanabara Koogan, 2012.

KENSKI, V. M. Tecnologias e ensino presencial e a distância. Campinas: Papirus, 2003.

KLOPFER, E.; OSTERWEIL, S.; SALEN, K. Moving learning games forward: obstacles, opportunities \& openness. Boston, MA: The Education Arcade, 2009. Disponível em: https://education.mit.edu/wpcontent/uploads/2018/10/MovingLearningGamesForward_EdArcade.pdf. Acesso em: 28 fev. 2020.

KRASILCHIK, M. Prática de ensino de biologia. São Paulo: Editora da Universidade de São Paulo, 2008.

LALUZELA, J. L; CRESPO, I; CAMPS. S. As tecnologias da informação e da comunicação e os processos de desenvolvimento e socialização. In: COLL, C. et al. Psicologia da educação virtual: aprender e ensinar com as novas tecnologias da informação e da comunicação. Porto Alegre: Artmed, p. 47-65, 2010.

LEÃO, G. M. C. Diferentes estratégias metodológicas para o processo de ensino e aprendizagem da Biologia celular. Tese (Doutorado) -Universidade Federal de Curitiba, Curitiba, 2018. Disponível em: https://www.acervodigital.ufpr.br/bitstream/handle/1884/55446/R\%20- 
\%20T\%20\%20GABRIEL\%20MATHIAS\%20CARNEIRO\%20LEAO.pdf?sequence=1\&is Allowed=y. Acesso em: 04 mar. 2020.

LÉVY, P. As tecnologias da inteligência: o futuro do pensamento na era da informática. Rio de Janeiro: Editora 34, 2010.

MEIR, E. et al. How effective are simulated molecular-level experiments for teaching diffusion and osmosis? Cell Biology Education. n. 4, p. 235-248, Fall, 2005. Disponível em:

https://www.ncbi.nlm.nih.gov/pmc/articles/PMC1200778/pdf/i1536-7509-4-3235.pdf. Acesso em: 07 abr. 2020.

MELLO, V. Histórico e discussão do conceito de jogabilidade em videogames. 2013. Dissertação (Mestrado) Faculdade de Comunicação Social, Centro de Educação e Humanidades, Universidade do Estado do Rio de Janeiro, Rio de Janeiro, 2013. Disponível em:

http://www.bdtd.uerj.br/tde_busca/arquivo.php?codArquivo=6597. Acesso em: $10 \mathrm{dez} .2019$.

PETROVICH, A.C.; ARAUJO, M. F. F.; MONTENEGRO, L. A.; ROCHA, A.C.P.; PINTO, E.D.J. Temas de difícil ensino e aprendizagem em ciências e biologia: experiências de professores em formação durante o período de regência. Revista de Ensino de Biologia da Associação Brasileira de Ensino de Biologia (SBEnBio), Niterói, v.7, p.363-373, 2014.

PRENSKY, M. Não me atrapalhe, mãe - Eu estou aprendendo! São Paulo: Phorte, 2010.

SHAFFER, D. W.; GEE, J.: The Right Kind of GATE: Computer Games and the Future of Assessment. In: Mayrath, M., Robinson, D., Clarke-Midura, J. (eds.).

Technology-Based Assessments for 21st Century Skills: Theoretical and Practical Implications from Modern Research. Charlotte, NC, US: Information Age Publishers, 2012. Disponível em: https://www.researchgate.net/publication/303856430_The_Right_Kind_of_GAT E_Computer_games_and_the_future_of_assessment. Acesso em: $11 \mathrm{dez} .2019$.

SOARES, M. H. F. B. Jogos e atividades para ensino de química. Goiânia: Kelps, 2013.

SOUZA, M. T.; MARCELINO, R.; FORTUNATO, I. O LORI como método de avaliação de objeto de aprendizagem: estudo de revisão. Revista de Estudos Aplicados em Educação, v. 3, n. 5, jan./jun. 2018. Disponível em:

file:///Users/mirianpacheco/Downloads/5002-Texto\%20do\%20Artigo-17167-110-20180815.pdf. Acesso em: 20 ago. 2020.

VIGÁRIO, A. F. As tramas do ensino de biologia celular na educação básica: conteúdos específicos, prática pedagógica e formação de professores/as. 2017. 242 f. Tese (Doutorado em Educação) - Universidade Federal de Uberlândia, Uberlândia, 2017. Disponível em: 
Recebido: 03 jun. 2020

Aprovado: 03 nov. 2020

DOI: $10.3895 /$ actio.v5n3.12493

Como citar:

ALBRECHT, M. P. S.; OLIVEIRA, F. E. de. Jogo eletrônico para o ensino de Biologia Celular. ACTIO

Curitiba, v. 5, n. 3, p. 1-18, set./dez. 2020. Disponível em: <https://periodicos.utfpr.edu.br/actio>. Acesso em:

$\mathrm{XXX}$

Correspondência:

Mirian Pacheco Silva Albrecht

Rua Marechal Deodoro, 686, apto 106. Bairro Santa Paula. São Caetano do Sul. Brasil.

Direito autoral: Este artigo está licenciado sob os termos da Licença Creative Commons-Atribuição 4.0

Internacional.

(c) (1) 